\title{
Pyloric regurgitation and gastric ulcer
}

\author{
F. J. FLINT AND P. GRECH \\ From the Northern General Hospital, Sheffield
}

SUMMARY Using a radiological test for pyloric regurgitation described by Capper, Airth, and Kilby (1966), it was confirmed that the pylorus is normally competent but incompetent in gastric ulcer and chronic alcoholic gastritis and often incompetent in chronic duodenal ulcer. The significance of pyloric regurgitation in the aetiology of gastric ulcer is discussed.

The association between gastric ulcer and ulceration or deformity of the pylorus or duodenum is well known. The theory that gastric ulcer associated with pyloro-duodenal deformity is due to stasis was not supported by the work of Capper and his colleagues (Capper, 1967) who found evidence of stasis in only $7 \%$ of 83 cases. They suggested that gastric ulcer might be due to bilious regurgitation which, under experimental conditions in dogs, was shown by Lawson (1964) to cause gastritis. A radiological technique for assessing the degree of competence of the pylorus was devised whereby barium was injected into the duodenum through a fine-bore tube which had been swallowed and encouraged to pass through the pylorus (Capper et al, 1966; Capper, 1967). Contrary to traditional teaching, the pylorus was normally competent but, in gastric ulcer, pyloric regurgitation was the rule. Thus, in 26 persons without dyspepsia, there was no reflux; in 18 cases of ulcer of the body of the stomach associated with pyloro-duodenal deformity, reflux was observed in every case; in 37 cases of benign gastric ulcer without pyloro-duodenal deformity, reflux was evident in 35 and was more pronounced in the erect than in the supine posture. It was suggested that bilious reflux might be an important factor in the aetiology of gastric ulcer.

It seemed to us reasonable to repeat the work of Capper, using a similar technique, in order to confirm or refute such a revolutionary concept.

Received for publication 22 December 1969.

\section{Material and Methods}

A group of persons without dyspepsia was compared with four groups of patients with gastric ulcer associated with pyloro-duodenal deformity, gastric ulcer without such deformity, chronic duodenal or juxtapyloric ulcer, and chronic alcoholic gastritis. The nature of the deformity of the pyloric region was a scar from old ulceration in three, Billroth I gastrectomy in two, and anastomosis to the jejunum in another. This report concerns 56 cases (Table).

The technique was similar to that described by Capper et al (1966) with minor modifications. The patient was prepared as for a normal barium meal. He sucked a lignocaine lozenge before the

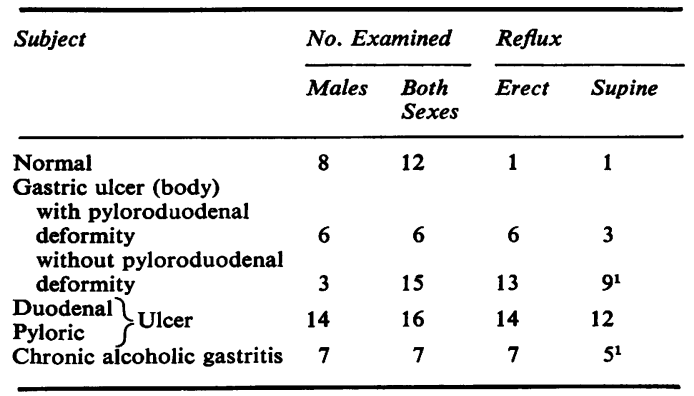

Table Results in 56 cases of pyloric intubation

${ }^{1}$ Erect $>$ supine in all cases. 
examination but sedation was unnecessary. A fine, soft rubber tube of $1 \mathrm{~mm}$ bore with a terminal mercury balloon was swallowed to allow the mercury balloon to pass into the duodenum. The patient was then made to lie down on his right side for 15 to 20 minutes when the bulb was usually through the pylorus. Enough length of the tubing was given to allow the balloon to reach the junction of the second and third part of the duodenum. When the aperture in the tube

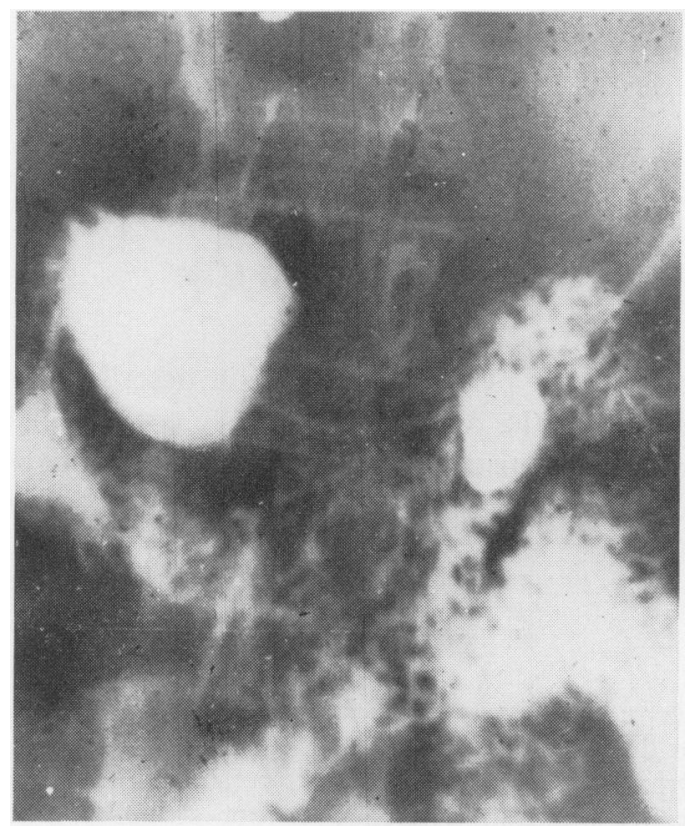

Fig. 1 Competent pylorus in one of the controls. Note the mercury balloon in the third part of the duodenum.

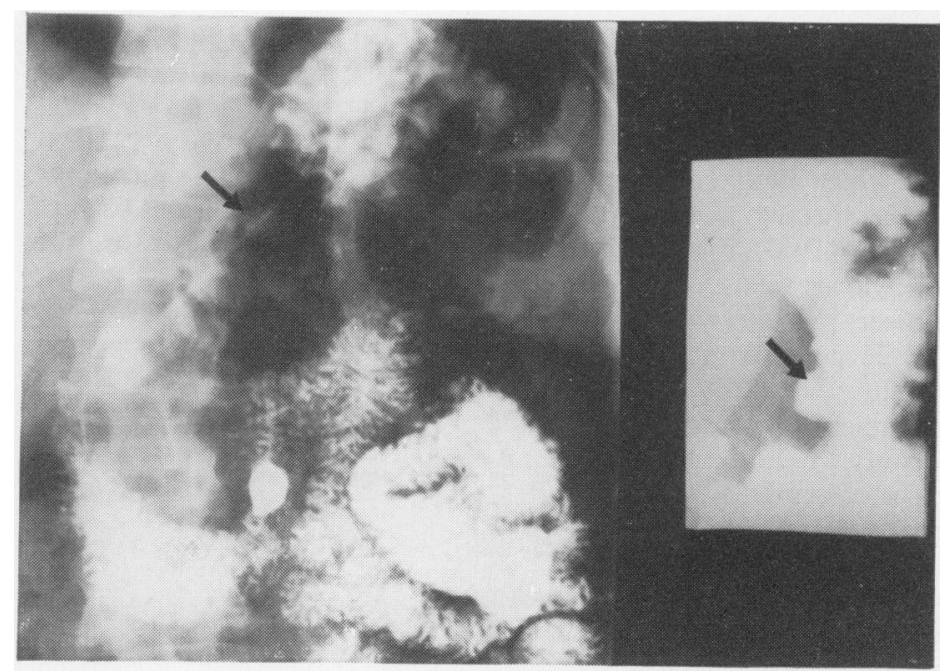

Fig. 2 Incompetent pylorus in a case of gastric ulcer on the posterior wall of the stomach. Ulcer crater is well etched by the barium (arrow). Inset shows the ulcer in profile. was lying freely in the duodenal cap $20 \mathrm{ml}$ of a weak barium solution was injected. The examina- $\Omega$ tion was first carried out with the patient standing $\stackrel{?}{\rightleftharpoons}$ and afterwards it was repeated with the patient $\overrightarrow{\vec{F}}$ in the supine position. The examination was $\stackrel{5}{?}$ carried out under fluoroscopy with an image- $\frac{?}{?}$ intensifier and a television output. The movement $\frac{\bar{\sigma}}{\bar{c}}$ of the barium bolus was first observed, and the $\frac{\hat{\sigma}}{\widehat{D}}$ presence, rate, and direction of any peristaltic $\propto$ waves along the duodenum were recorded. The $\%$ patient was screened for three minutes in both $\vec{\circ}$ the erect and the supine posture unless excessive reflux was demonstrated, when the screening $\omega$ time was reduced.

\section{Results}

Capper's contention that the pylorus is normally competent was confirmed (Fig. 1 and Table). o Pyloric reflux was prominent in nearly all cases of ulcer of the body whether or not there was deformity of the pyloric area. It was more pronounced in the absence of pyloroduodenal deformity, especially in the erect posture when there were usually four to six retroperistaltic contractions per minute compared with one or two or even none in the supine (Fig. 2). The test was repeated in four patients whose gastric ulcer had healed; reflux was still present but reduced.

In all cases of chronic alcoholic gastritis pyloric regurgitation was prominent.

In 16 patients with duodenal or juxtapyloric ulcer without ulceration of the body of the stomach, selected because of chronicity or deformity, reflux was evident in 14 but was never so pronounced as in those with gastric ulcer and was not influenced by posture. No patient with a duodenal ulcer of recent onset was examined. When the pylorus was stenosed it was impossible to pass the tube into the duodenum.

Most patients with gastric ulcer were examined by gastroscopy and bilious reflux was usually observed. This was particularly striking in the case shown in Fig. 3 where the gastric ulcer is seen proximal to the stoma adjoining a loop of jejunum to which the common bile duct had been anastomosed after removal of the pancreas. Gastroscopy, however, is not a satisfactory method of assessing pyloric reflux when a vagal blocking drug is used.

\section{Discussion}

It is unlikely that a gastric ulcer proximal to the incisura could cause pyloric reflux. It is more likely that reflux causes ulceration. Regurgitation is most pronounced in those cases of gastric 


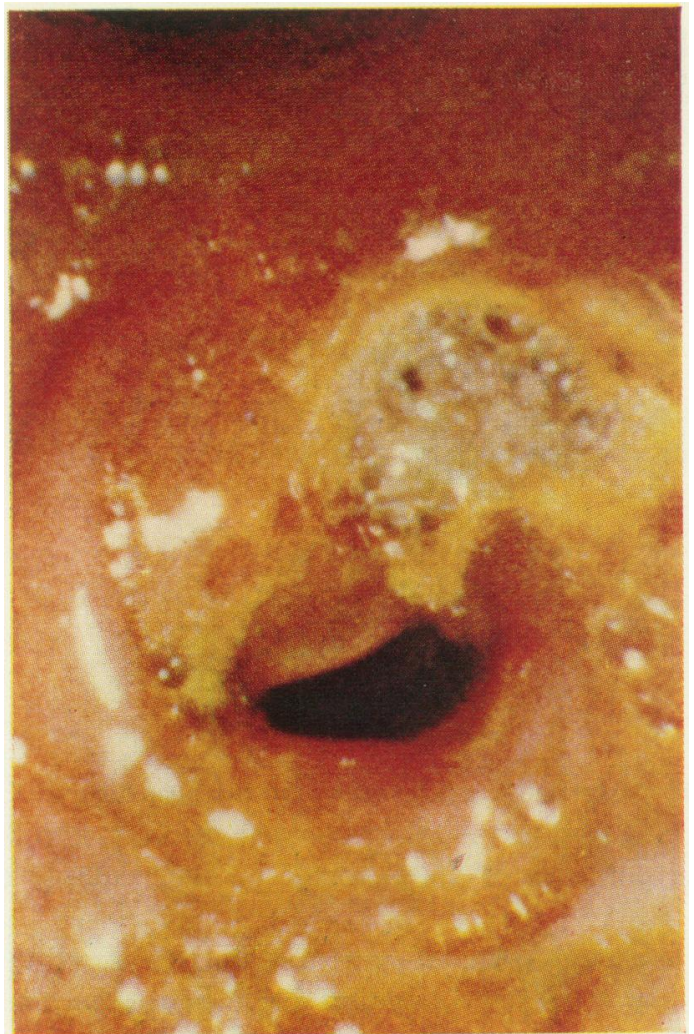

Fig. 3 Gastrophotograph showing gastric ulcer proximal to stoma with bilious reflux.

ulcer even when no pyloric deformity can be demonstrated.

Assessing pyloric reflux by such an artificial means might not be considered relevant to normal conditions. However, Watkinson (1951) using a 24-hour test meal in patients eating normal meals, found that bile staining was normally infrequent but common in gastric ulcer. More recently, Rhodes, Barnado, Phillips, Rovelstead, and Hofman (1968), measuring bilious regurgitation after meals with bile salt pool labelled with ${ }^{14} \mathrm{C}$ chenodeoxycholic acid, found a sixfold increase in cases of gastric ulcer compared with normal controls. DuPlessis (1962) demonstrated that after gastrectomy bilious reflux causes gastritis.

It is postulated that excessive bilious reflux is a factor in the aetiology of gastric ulcer even if the pylorus is healthy but the mechanism is unknown. Gastric ulceration occurs only in the presence of acid, even though the output is low, so it is probable that bile salts injure the mucosal barrier against acid. Davenport (1968) showed experimentally that bile salts break the physico-chemical barrier of the gastric mucosa, allowing $\mathrm{H}^{+}$ions to pass into the mucosal wall. This causes mucosal damage (Overholt and Pollard, 1968). Bile salts are also probably injurious to the oesophagus (Gillison, Airth, Gibson, Capper, and Bradford, 1969).

Clearly, excessive bilious gastric reflux can no longer be regarded as a benign and physiological process. Bile salts may apparently damage the defences of the gastric mucosa with subsequent erosion by acid. More information is required on the relationship between the degree of pyloric regurgitation and exacerbations and remissions of gastric ulcer. That recumbency reduces pyloric reflux and carbenoxolone is excreted in the bile may be relevant to the effectiveness of these measures in treatment.

\section{References}

Capper, W. M., Airth, G. R., and Kilby, J. O. (1966). A test for pyloric regurgitation. Lancet, 2, 621-623.

Capper, W. M. (1967). Dyspepsia. Hospital Med., 1, 1053-1057.

Davenport, H. W. (1968). Destruction of the gastric mucosa barrier by detergents and urea. Gastroenterology, 54, 175-181.

DuPlessis, D. J. (1962). Gastric mucosal changes after operations on the stomach. $S$. African med. J., 36, 471-478.

Gillison, E. W., Airth, G. R., Gibson, M. J., Capper, W. M., and Bradford, I. (1969). Hiatus hernia and heartburn. Gut, 10, 609-613.

Overholt, B. F., and Pollard, H. M. (1968). Acid diffusion into the human gastric mucosa. Gastroenterology, 54, 182-189.

Lawson, H. H. (1964). Effect of duodenal contents on gastric mucosa under experimental conditions. Lancet, 1, 469-472.

Rhodes, J., Barnado, D. E., Phillips, S. F., Rovelstead, R. A., and Hofman, A. F. (1968). Increased reflux of bile into the stomach in gastric ulcer. Gut, 9, 737.

Watkinson, G. (1951). A study of the changes in $p \mathrm{H}$ of gastric contents in peptic ulcer. Gastroenterology, 18, 377-390. 